\title{
A comparative radiological study of the pubic symphysis in rheumatic disorders
}

\author{
D. L. SCOTT, C. J. EASTMOND, AND V. WRIGHT
}

From the Rheumatism Research Unit, Leeds

SUMMARY Radiological abnormalities are often seen at the pubic symphysis in rheumatic disorders. In a radiological study of 120 patients with rheumatic diseases osteitis pubis with erosive and sclerotic changes was a feature of ankylosing spondylitis. Irregularity and subluxation were not related to osteitis pubis or diagnostic group but were common in females and had a possible association with previous pregnancy.

The radiological changes at the pubic symphysis of osteitis pubis have been recognised for more than 50 years. Early reports related osteitis pubis to urological disease, prostatectomy, and pelvic surgery. Subsequently other causes have been described, including pregnancy and trauma (Wiltse and Frantz, 1956; Coventry and Mitchell, 1961; Harris and Murray, 1974).

A number of rheumatic disorders have been associated with radiological abnormalities of the pubic symphysis. The commonest of these are ankylosing spondylitis, rheumatoid arthritis, and to a less extent osteoarthritis (Coventry and Mitchell, 1961; Dilsen, et al. 1962). But there is little detailed information on the nature, frequency, extent, and interrelationships of abnormalities at the pubic symphysis in these diseases.

In the present study radiological changes at the pubic symphysis have been examined in patients with ankylosing spondylitis, rheumatoid arthritis, and osteoarthritis. Pain of insidious or sudden onset is the predominant symptom associated with osteitis pubis, and the significance of this has been considered in relation to the radiological changes. As pregnancy and trauma are 2 causes of osteitis pubis which could also be involved in at least some patients, the possible significance of these factors has also been considered.

Radiological fluffy periostitis of the inferior pubic ramus is an additional feature considered to be associated with ankylosing spondylitis (Dilsen et al., 1962). Radiographs have been analysed in the present study for such changes and their relationship to changes at the symphysis pubis considered.

Accepted for publication 5 January 1979.

Correspondence to Dr D. L. Scott, The Rheumatism Research Unit, 36 Clarendon Road, Leeds LS2 9PJ.

\section{Patients and methods}

One hundred and twenty sequential patients attending rheumatology clinics in Yorkshire were examined clinically and radiologically to form 40 patients in each of the 3 diagnostic groups, with equal numbers of males and females. All patients with ankylosing spondylitis had definite disease as defined by the New York criteria (Bennett and Burch, 1967). Those with rheumatoid arthritis had classical or definite disease according to the American Rheumatism Association (Ropes et al., 1958). Patients with osteoarthritis had polyarticular peripheral joint involvement with or without degenerative disease of the spine.

A full clinical examination of each patient was performed and details of age, sex, and disease duration recorded. The presence at any time of pain from the pubic symphysis was noted. Details of trauma to the pubic symphysis and pregnancies were also recorded.

Anteroposterior radiographs of the pelvis were read by 2 observers (D.L.S. and C.J.E.) according to the techniques previously described by the Leeds group (Macrae et al., 1971). Changes at the sacroiliac joints, the pubic symphysis, and the inferior pubic rami were recorded. Changes at the sacroiliac joints were graded according to the New York criteria (Bennett and Burch, 1967). The changes recorded at the inferior pubic rami were either irregularity or periostitis. When there was fluffy periostitis it was recorded as mild, moderate, or severe in degree.

The maximum width of the pubic symphysis was measured to the nearest millimetre. Irregularity of the joint margins of the symphysis, when present, was recorded as slight, mild, moderate, or severe in 


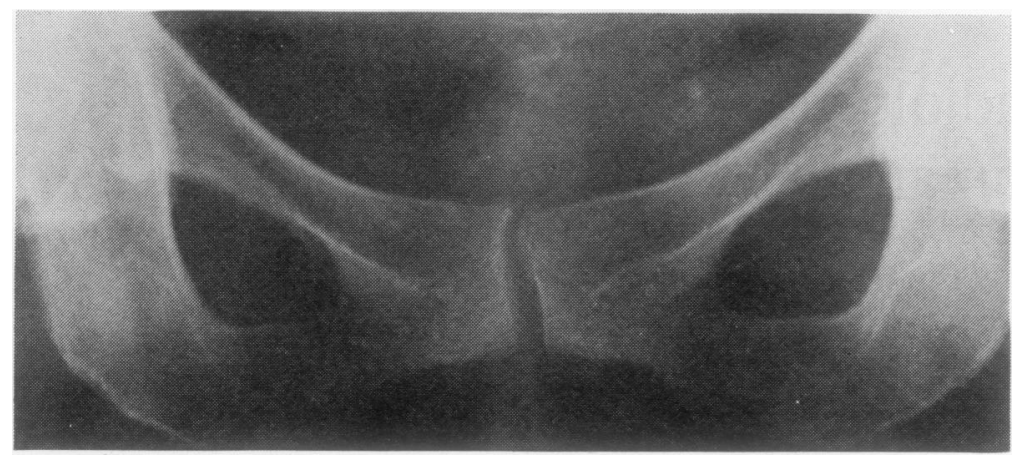

Fig. 1 Grade 1 osteitis pubis in a female with rheumatoid arthritis for 15 years. There is moderate irregularity of the pubic symphysis

degree. Fig. 1 shows an example of moderate irregularity. Subluxation was considered present when the superior or inferior joint margins were malaligned. It was recorded as: superior margin only; both margins with less than $50 \%$ subluxation; both margins with greater than $50 \%$ subluxation.

A standardised grading system for osteitis pubis based on the presence of sclerosis and erosion of the joint margin was devised. It was as follows:

Grade 0: Normal.

Grade 1: Minimal sclerosis alone; minimal erosion alone; or both possible sclerosis and possible erosion.

Grade 2: Moderate sclerosis with or without possible erosion; moderate erosion with or without possible sclerosis; both minimal sclerosis and minimal erosions.

Grade 3: Severe sclerosis with minimal erosions; severe erosions with minimal sclerosis; or both moderate sclerosis and moderate erosions.

Grade 4: Severe sclerosis with moderate erosions; severe erosions with moderate sclerosis; or total ankylosis.

Examples of these grades are shown in Figs. 1-4 in patients with ankylosing spondylitis.

\section{Results}

Details of the patients in the study are given in
Table 1. The duration of the disease was similar $\stackrel{\omega}{\infty}$ in each group, though the average age of patients with ankylosing spondylitis was about 20 years less than in the other groups. Trauma to the pubic symphysis was equally uncommon in all groups. Pain at the pubic symphysis occurred quite often in all groups and was commoner among the women than the men, though it did not differ in frequency between the groups. Pain and trauma were not related to any radiological change at the pubic symphysis. Table 2 shows the grading of radiologicas sacroiliitis in the study.

Osteitis pubis was commonest in ankylosin

Table 2 The incidence and grade of sacroillitis in patients by diagnostic groups. Only patients with ankylosing spondylitis had bilateral changes

\begin{tabular}{|c|c|c|c|c|c|c|}
\hline \multirow[t]{2}{*}{ Grade } & \multicolumn{2}{|c|}{$\begin{array}{l}\text { Ankylosing } \\
\text { spondylitis }\end{array}$} & \multicolumn{2}{|c|}{$\begin{array}{l}\text { Rheumatoid } \\
\text { arthritis }\end{array}$} & \multicolumn{2}{|c|}{ Osteoarthritis } \\
\hline & Males & Females & Males & Females & Males & Females \\
\hline 0 & 0 & 0 & 13 & 17 & 17 & 20 \\
\hline 1 & 0 & 0 & $7 *$ & $2^{*}$ & $3^{*}$ & 0 \\
\hline 2 & 0 & 2 & 0 & $1^{*}$ & 0 & 0 \\
\hline 3 & 2 & 2 & 0 & 0 & 0 & 0 \\
\hline 4 & 18 & 16 & 0 & 0 & 0 & 0 \\
\hline
\end{tabular}

* Unilateral changes only.

Table 1 Details of age, disease duration, and pain and trauma involving the pubic symphysis in males and females by diagnostic group

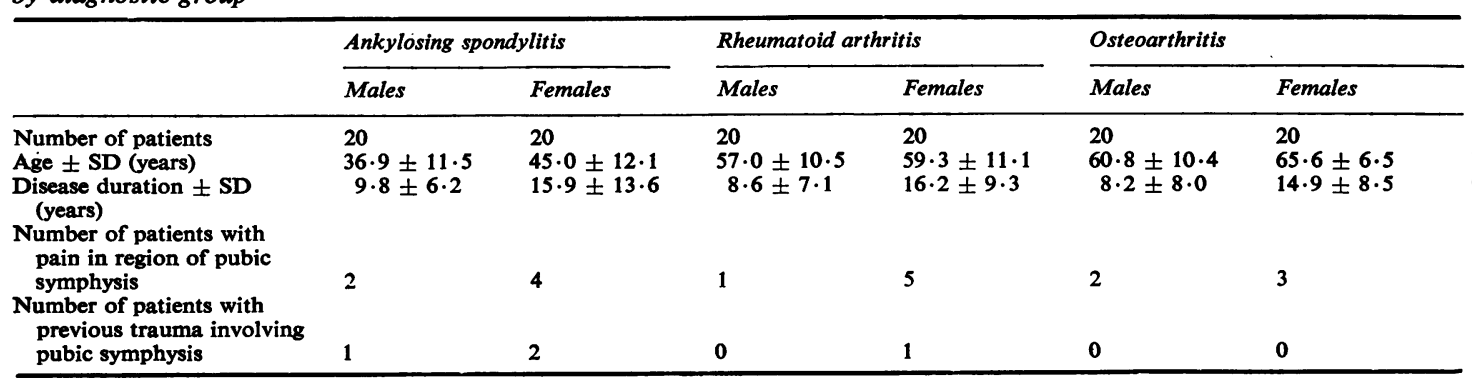




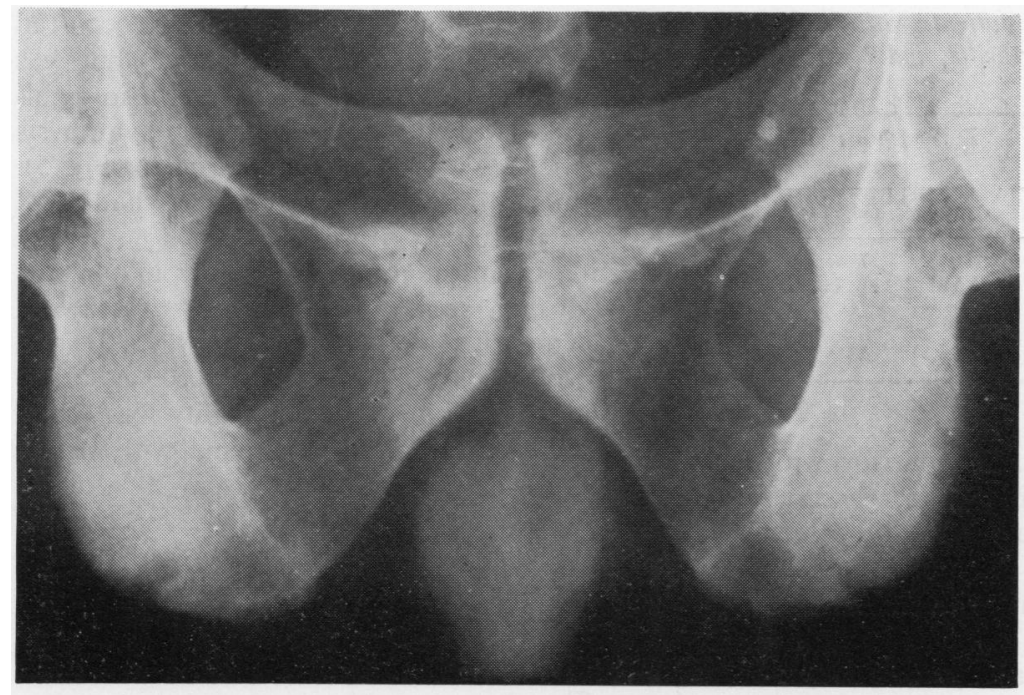

Fig. 2 Grade 2 osteitis pubis in a male with ankylosing spondylitis for 15 years. There is minimal sclerosis and erosions

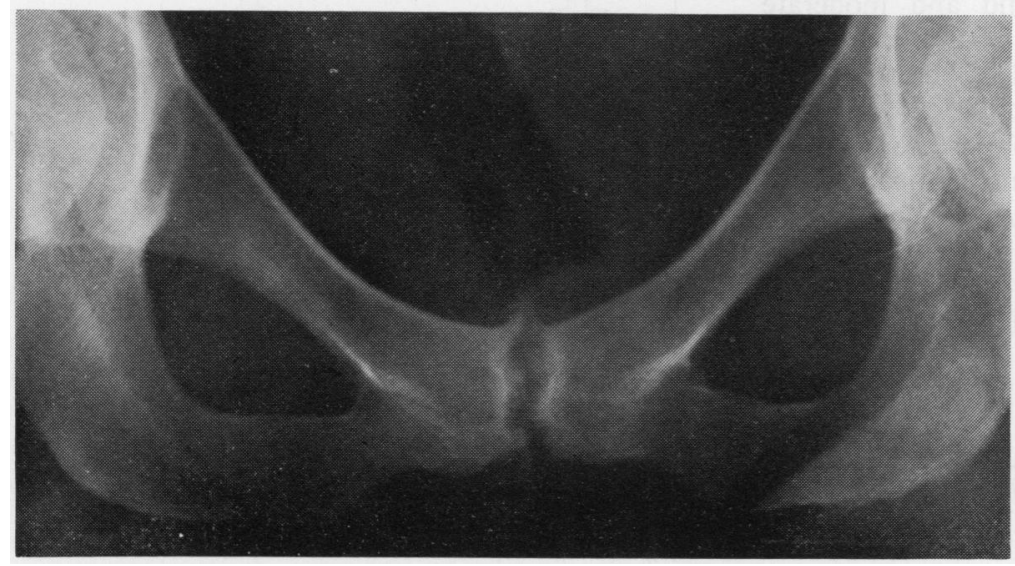

Fig. 3 Grade 3 osteitis pubis in a female with ankylosing spondylitis for 13 years. There are severe erosions and minimal sclerosis

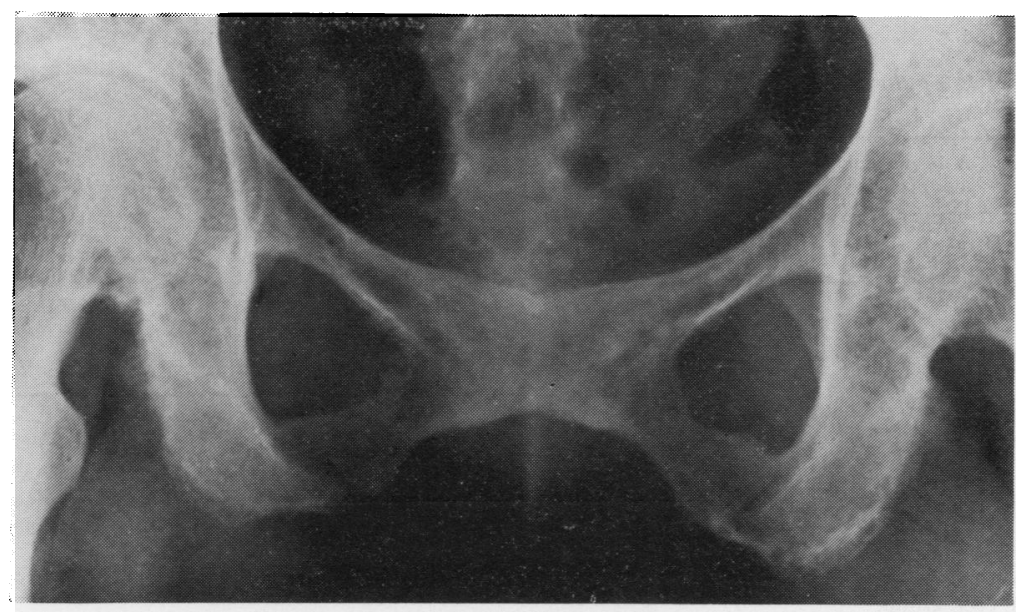

Fig. 4 Grade 4 osteitis pubis in a female with ankylosing spondylitis for 18 years. There is ankylosis of the symphysis 
Table 3 Grading of osteitis pubis in patients with ankylosing spondylitis, rheumatoid arthritis, and osteoarthritis

\begin{tabular}{|c|c|c|c|c|c|c|}
\hline \multirow[t]{2}{*}{ Grade } & \multicolumn{2}{|c|}{$\begin{array}{l}\text { Ankylosing } \\
\text { spondylitis }\end{array}$} & \multicolumn{2}{|c|}{$\begin{array}{l}\text { Rheumatoid } \\
\text { arthritis }\end{array}$} & \multicolumn{2}{|c|}{ Osteoarthritis } \\
\hline & Males & Females & Males & Females & Males & Females \\
\hline 0 & 2 & 4 & 14 & 13 & 15 & 7 \\
\hline 1 & 7 & 7 & 3 & 5 & 5 & 11 \\
\hline 2 & 6 & 0 & 3 & 1 & 0 & 2 \\
\hline 3 & 5 & 4 & 0 & 1 & 0 & $\mathbf{0}$ \\
\hline 4 & 0 & 5 & 0 & 0 & 0 & 0 \\
\hline
\end{tabular}

spondylitis, as shown in Table 3. Comparison with patients with rheumatoid arthritis gives $\chi^{2}=26 \cdot 8$ (4 DF), $P<0.001$, and with patients with osteoarthritis gives $\chi^{2}=25 \cdot 3$ (4 DF), $P<0.001$. No difference was found between patients with rheumatoid arthritis and osteoarthritis.

Irregularity and subluxation at the pubic symphysis were not related to osteitis pubis or to any particular diagnostic group. Mild and moderate degrees of irregularity occurred in $30 \%$ of the 60 female patients compared with $11.7 \%$ of 60 male patients giving $\chi^{2}=5.05, \quad P<0.05$ (Table 4). Subluxation of the pubic symphysis was present in $21.7 \%$ of the 60 female patients compared with $3.3 \%$ of the 60 male patients $\chi^{2}=4 \cdot 27, P<0.05$ (Table 5). Both irregularity and subluxation occurred more commonly in females who had had children, but the differences were not significant (Table 6).

Table 4 Distribution of irregularity of the pubic symphysis related to sex

\begin{tabular}{llccl}
\hline $\begin{array}{l}\text { Degree of } \\
\text { irregularity }\end{array}$ & Absent & Slight & Mild & Moderate \\
\hline Males & 49 & 4 & 5 & 2 \\
Females & 27 & 15 & 15 & 3 \\
\hline
\end{tabular}

Table 5 Distribution of subluxation of the pubic symphysis related to sex

\begin{tabular}{llcl}
\hline $\begin{array}{l}\text { Degree of } \\
\text { subluxation }\end{array}$ & Absent & $\begin{array}{l}\text { Upper margin } \\
\text { only }\end{array}$ & $\begin{array}{l}\text { Both margins } \\
\text { less than 50\% }\end{array}$ \\
\hline Males & 58 & 0 & 2 \\
Females & 46 & 11 & 3 \\
\hline
\end{tabular}

Table 6 The distribution of irregularity and subluxation of the pubic symphysis in females in relation to pregnancy

\begin{tabular}{lll}
\hline Number of children & $\begin{array}{l}\text { Percentage with } \\
\text { irregularity }\end{array}$ & $\begin{array}{l}\text { Percentage with } \\
\text { subluxation }\end{array}$ \\
\hline $\begin{array}{l}\text { None (15) } \\
\text { One or more (45) }\end{array}$ & \begin{tabular}{ll}
$33 \cdot 3 \%(5)$ & $13 \cdot 3 \%(2)$ \\
\hline
\end{tabular} & $24 \cdot 4 \%(11)$ \\
\hline
\end{tabular}

The figures in parentheses give the number in each group.
Marked widening of the pubis symphysis occurred in 2 patients with ankylosing spondylitis, but was not related to osteitis pubis. There were no significant differences in width of the pubic symphysis between patients with the 3 diseases studied (Fig. 5). One woman with ankylosing spondylitis had total ankylosis of the pubic symphysis.

Periostitis occurred more commonly in patients with ankylosing spondylitis than in those with rheumatoid arthritis $\left(\chi^{2}=13 \cdot 76,2 \mathrm{DF}, \mathrm{P}<0.01\right)$ and osteoarthritis $\left(\chi^{2}=32 \cdot 28,2 \mathrm{DF}, \mathrm{P}<0 \cdot 001\right)$ as shown in Table 7. No radiological abnormality was found in the pubic rami of the $\mathbf{4 0}$ patients with osteoarthritis, which is significantly less than $20 \%$ of the
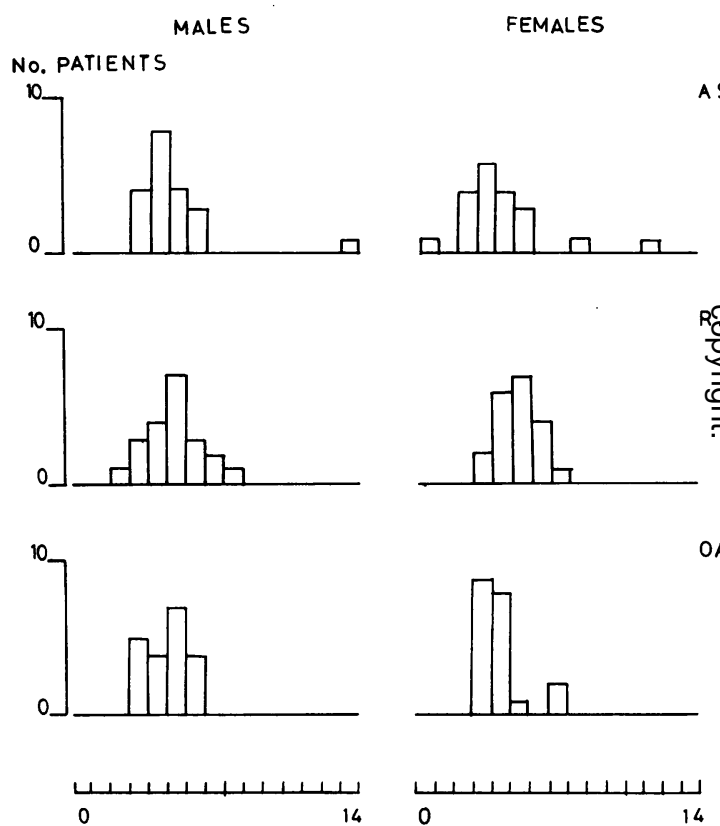

SYMPHYSIS WIDTH $(\mathrm{mm})$

Fig. 5 An analysis of the width of the pubic symphysis (in millimetres) in patients with ankylosing spondylitis, rheumatoid arthritis, and osteoarthritis

Table 7 Details of radiological changes at the inferior pubic rami in patients with ankylosing spondylitis, rheumatoid arthritis, and osteoarthritis

\begin{tabular}{llll}
\hline $\begin{array}{l}\text { Radiological changes } \\
\text { at the inferior } \\
\text { pubic rami }\end{array}$ & $\begin{array}{l}\text { Ankylosing } \\
\text { spondylitis }\end{array}$ & $\begin{array}{l}\text { Rheumatoid } \\
\text { arthritis }\end{array}$ & $\begin{array}{l}\text { Osteo- } \\
\text { arthritis }\end{array}$ \\
\hline $\begin{array}{l}\text { Normal or irregularity } \\
\text { Mild periostitis }\end{array}$ & 17 & 32 & 40 \\
$\begin{array}{l}\text { Moderate and } \\
\text { severe periostitis }\end{array}$ & 13 & 7 & 0 \\
\hline
\end{tabular}


40 patients with rheumatoid arthritis with mild or moderate changes $\left(\chi^{2}=8 \cdot 88,2 \mathrm{DF}, \mathrm{P}<0 \cdot 02\right)$ (Table 7). Radiological changes at the inferior pubic ramus were not related to the presence or absence of osteitis pubis.

\section{Discussion}

Previous radiological studies of the symphysis pubis have considered abnormalities of this joint without regard to the type of changes (Wilkinson and Bywaters, 1958; Hart and Robinson, 1959; Dilsen et al., 1962; Calin et al., 1977a). It is possible that the various changes seen in this joint result from 1 pathological process and represent different stages in the cause of this disorder. The finding, however, that irregularity and subluxation at the pubic symphysis were not associated with erosion and sclerosis suggests that these radiological abnormalities represent the result of at least 2 distinct disorders.

Osteitis pubis as characterised radiologically by erosion and sclerosis of the joint margin is significantly more common in patients with ankylosing spondylitis than with rheumatoid arthritis and osteoarthritis. Moderate and severe changes were almost totally confined to patients with ankylosing spondylitis. The lack of symptoms associated with radiological osteitis pubis is in agreement with the findings of Coventry and Mitchell (1961), who consider osteitis pubis to have a varied clinical course, with asymptomatic forms being common.

The finding that erosive osteitis pubis was not associated with previous trauma and pregnancies suggests that they are not major factors in its pathogenesis. The pubic symphysis is anatomically similar to the sacroiliac and manubrio-sternal joints. The high frequency of radiological osteitis pubis in ankylosing spondylitis suggests that involvement of these joints has a common aetiology.

Irregularity and subluxation of the pubic symphysis were both commoner in females in all diagnostic groups. They were also commoner, but not significantly so, in those females who had been pregnant than in those who had not. The number of patients with more than 2 previous pregnancies were too small for meaningful statistical analysis. It is possible that irregularity and subluxation of the pubic symphysis result from the laxity of this joint during pregnancy. A study of females with repeated pregnancies would help in evaluating this possibility.

Periostitis at the inferior pubic rami is generally considered a feature of ankylosing spondylitis (Dilsen et al., 1962; McEwen et al., 1971), resulting from inflammatory disease at the enthesis (Ball, 1971). Recent studies by Calin et al. (1977b), however, suggested that periostitis at this site is not a feature related to ankylosing spondylitis. The results of the present study suggest the opinion that moderate and severe periostitis at the inferior pubic rami are features of ankylosing spondylitis.

The finding of mild periosteal reaction at the inferior pubic ramus more frequently in patients with rheumatoid arthritis than in those with osteoarthritis suggests that mild periostitis could be a feature of chronic inflammatory arthritides rather than degenerative disease. These findings indicate that it is important when studying radiological periostitis to note not only its presence or absence but also its severity.

\section{Conclusions}

The results of the present study show: (1) Erosive osteitis pubis is a radiological feature of ankylosing spondylitis and is probably of common aetiology to the sacroiliitis and other joint manifestations. (2) Irregularity and subluxation of the pubic symphysis are not specific features of ankylosing spondylitis. (3) Irregularity and subluxation of the pubic symphysis are commoner in females than in males and may be related to previous pregnancies. (4) Moderate and severe periostitis of the inferior pubic ramus is a feature of ankylosing spondylitis, but milder periosteal reaction is possibly associated with chronic inflammatory arthritis in general.

\section{References}

Ball, J. (1971). Enthesopathy of rheumatoid and ankylosing spondylitis. Annals of the Rheumatic Diseases, 30, 213-223.

Bennett, P. H., and Burch, T. A. (1967). New York symposium on population studies in rheumatic diseases: diagnostic criteria. Bulletin on Rheumatic Diseases, 17, 453-458.

Calin, A., Bennett, P. H., Jupiter, J., and Terasaki, P. I. (1977a). HLA B27 and sacroiliitis in Pima Indiansassociation in males only. Journal of Rheumatology, 4, Suppl. 3, 44-48.

Calin, A., Fries, J. F., Schurman, D., and Payne, R. (1977b). The close association between symptoms and disease expression in HLA B27 positive individuals. Journal of Rheumatology, 4, 277-281.

Coventry, M. B., and Mitchell, W. C. (1961). Osteitis pubis. Journal of the American Medical Association, 178, 898-905.

Dilsen, N., McEwen, C., Poppel, M., Gersh, W. J., Di Tata, D., and Carmel, P. (1962). A comparative roentgenologic study of rheumatoid arthritis and rheumatoid (ankylosing) spondylitis. Arthritis and Rheumatism, 5, 341-368.

Harris, N. H., and Murray, R. O. (1974). Lesions of the symphysis in athletes. British Medical Journal, 4, 211-214.

Hart, D. F., and Robinson, K. C. (1959). Ankylosing spondylitis in women. Annals of the Rheumatic Diseases, 18, 15-23.

Kormano, M. (1971). Radiographic appearance of the pubic symphysis in old age and in rheumatoid arthritis. Acta Rheumatologica Scandinavica, 17, 286-294. 


\section{Scott, Eastmond, Wright}

MacRae, I. F., Haslock, D. I., and Wright, V. (1971). Grading of films for sacroiliitis in population studies. Annals of the Rheumatic Diseases, 30, 58-66.

McEwen, C., Di Tata, D., Lingg, C., Porini, A., Good, A., and Rankin, T. (1971). Ankylosing spondylitis and spondylitis accompanying ulcerative colitis, regional enteritis, psoriasis and Reiter's disease. Arthritis and Rheumatism, 14, 291-318.

Ropes, M. W., Bennett, G. A., Cobb, S., Jacox, R., and
Jessar, R. A. (1958). 1958 revision of diagnostic criteria for rheumatoid arthritis. Bulletin on Rheumatic Diseases, 9, 175-176.

Wilkinson, M., and Bywaters, E. G. (1958). Clinical features and course of ankylosing spondylitis. Annals of the Rheumatic Diseases, 17, 209-228.

Wiltse, L. L., and Frantz, C. H. (1956). Non-suppurative osteitis pubis in the female. Journal of Bone and Joint Surgery, 38A, 500-516. 